\title{
Growth of primary school children: a validation of the 1990 references and their use in growth monitoring
}

\author{
Mary C J Rudolf, Tim J Cole, Aaron J Krom, Pinki Sahota, Jenny Walker
}

\begin{abstract}
Aims-To determine whether the British 1990 growth charts are valid for cross sectional and longitudinal use in primary school children.

Methods-A total of 694 children aged 7-10 years from 10 Leeds primary schools were weighed and measured annually over three years by an expert auxologist. SD scores were calculated using both the Tanner-Whitehouse (TW) and the revised British 1990 growth references.

Results-The growth of this sample of children approximated the 1990 growth reference, with mean (SD) scores for height 0.12 (1.01), weight 0.20 (1.07), and body mass index (BMI) 0.19 (1.12). By comparison, the TW standards exaggerated the height and weight centiles. There was minimal channel crossing for height in either direction with $1.0 \%$ crossing up at least one channel width (0.67 SDscores), and $0.2 \%$ down for height. However, there was clear evidence of weight and particularly BMI increasing with age between and within subjects, at rates of up to 0.1 SDscores per year.

Conclusions-This study supports the adoption of the new growth references, and their use longitudinally for height monitoring. It also highlights the increasing weight of the school age population as a public health issue.

(Arch Dis Child 2000;83:298-301)
\end{abstract}

Paediatrics, Leeds

Community and

Mental Health Trust,

Belmont House, 3-5

Belmont Grove, Leeds

LS2 9NP, UK

M C J Rudolf

Institute of Child

Health, London, UK

T J Cole

Leeds Grammar School, Leeds, UK A J Krom

Leeds Metropolitan University, Leeds, UK P Sahota

Leeds General Infirmary, Leeds, UK J Walker

Correspondence to: Dr Rudolf

Accepted 7 June 2000

Keywords: growth; growth standards; growth references; growth charts; obesity

In recognition of concerns that the British growth standards which had been in use since $1966^{12}$ were out of date, new reference curves were compiled in the early $1990 \mathrm{~s}^{3}$ No resources were available to identify and study the large representative sample of children required to compile new references, so data were used pragmatically from 12 sources across the UK. Attempts were made to ensure the sample was suitable sociodemographically, but as it had not been planned de novo, this could not be assured, and indeed the data deliberately excluded measurements of nonwhite children. The new references were published in $1995^{3-5}$ along with revised growth charts. They differ from the previous ones in terms of both height and weight, and over the last four years the new charts have been widely adopted throughout the country.
In addition to height and weight charts, BMI (body mass index) charts $^{4}$ have also been produced.

It is clearly important to see in reality how closely the growth of British children fits the new curves. In 1999 a study of young children aged 6-24 months was reported from Glasgow, ${ }^{6}$ which suggests that for the infant and toddler age group they are a great improvement on the older growth charts. The evidence is still awaited for children at older ages.

In 1996 the APPLES project ${ }^{7}$ received funding from the Northern and Yorkshire Region. This project is a health promotion programme designed to encourage healthy eating and physical activity among Leeds primary school children. As part of the evaluation process of APPLES, growth data were methodically collected on children in years 3 to 6 in participating schools. The data collected offered the opportunity to analyse these children's growth in the light of the new references. Furthermore, as the data were collected longitudinally over three years it was also possible to gain some further understanding of patterns of growth, and in particular the level of channel crossing exhibited by children over time. This information to date has only been analysed using French children's data.

The aims of this study therefore were:

- To compare the new British 1990 references with the older Tanner-Whitehouse standards
- To ascertain whether the TannerWhitehouse triceps skinfold standards (1962) remain appropriate for today's schoolchildren

- To ascertain how the longitudinal growth (including BMI) of children relates to the 1990 charts (which were derived from cross sectional data)

- To provide information regarding the frequency of "channel crossing" for height, weight, and BMI of British children.

\section{Methods}

SUBJECTS

All children in years 3 and 4 (aged 7 to 9 years) of 10 primary schools in Leeds were approached to participate in the evaluation of the APPLES programme. The schools had been selected on the basis that they were known to the investigators and had expressed interest in participating in the programme. The children were measured in July 1996, and measurements repeated in July 1997 and July 1998, 
Table 1 Anthropometry of Leeds children aged 7-11 years, 1996-98

\begin{tabular}{|c|c|c|c|c|c|c|c|}
\hline Age & $n$ & Height (1990) & Height (TW) & Weight (1990) & Weight $(T W)$ & $B M I$ (1990) & Triceps $(T W)$ \\
\hline \multicolumn{8}{|l|}{ Boys } \\
\hline $7+y$ & 30 & $0.36(0.98)$ & $0.63^{\star \star \star}(0.93)$ & $0.16(1.27)$ & $0.42(1.17)$ & $-0.06(1.20)$ & $0.57^{\star}(1.34)$ \\
\hline $8+y$ & 196 & $0.15^{\star}(0.91)$ & $0.45^{\star \star \star}(0.88)$ & $0.12(0.95)$ & $0.38^{\star \star \star}(0.93)$ & $0.05(0.97)$ & $-0.27^{\star \star \star}(1.10)$ \\
\hline $9+y$ & 320 & $0.18^{\star \star \star}(0.92)$ & $0.46^{\star \star \star}(0.91)$ & $0.21^{\star \star \star}(1.00)$ & $0.48^{\star \star \star}(1.00)$ & $0.16^{\star}(1.12)$ & $-0.18^{\star \star}(1.07)$ \\
\hline $10+y$ & 281 & $0.13^{\star}(0.94)$ & $0.38^{\star \star \star}(0.97)$ & $0.28^{\star \star \star}(1.02)$ & $0.56^{\star \star \star}(1.02)$ & $0.29^{\star \star \star}(1.14)$ & $-0.20^{\star \star}(1.10)$ \\
\hline $11+y$ & 148 & $0.17^{\star}(0.97)$ & $0.39^{\star \star \star}(1.05)$ & $0.31^{\star \star \star}(1.14)$ & $0.59^{\star \star \star}(1.15)$ & $0.28^{\star \star}(1.29)$ & $-0.19^{\star}(1.09)$ \\
\hline Total & 975 & $0.17^{\star \star \star}(0.93)$ & $0.43^{\star \star \star}(0.94)$ & $0.23^{\star \star \star}(1.03)$ & $0.50^{\star \star \star}(1.02)$ & $0.19^{\star \star \star}(1.13)$ & $-0.22^{\star \star \star}(1.10)$ \\
\hline \multicolumn{8}{|l|}{ Girls } \\
\hline $7+y$ & 25 & $-0.39(1.11)$ & $0.05(1.08)$ & $-0.15(0.99)$ & $0.01(1.05)$ & $0.11(0.86)$ & $0.00(1.02)$ \\
\hline $8+y$ & 164 & $-0.02(1.09)$ & $0.40^{\star \star \star}(1.07)$ & $-0.05(1.00)$ & $0.18^{\star}(1.04)$ & $-0.03(0.96)$ & $-0.06(0.94)$ \\
\hline $9+y$ & 263 & $0.06(1.06)$ & $0.47^{\star \star \star}(1.09)$ & $0.18^{\star \star}(1.12)$ & $0.44^{\star \star \star}(1.12)$ & $0.23^{\star \star \star}(1.11)$ & $-0.03(1.00)$ \\
\hline $10+y$ & 229 & $0.08(1.12)$ & $0.54^{\star \star \star}(1.24)$ & $0.21^{\star \star}(1.16)$ & $0.49^{\star \star \star}(1.17)$ & $0.22^{\star \star}(1.14)$ & $-0.26^{\star \star \star}(1.02)$ \\
\hline $11+y$ & 111 & $0.19(1.08)$ & $0.52^{\star \star \star}(1.27)$ & $0.44^{\star \star \star}(1.22)$ & $0.64^{\star \star \star}(1.25)$ & $0.44^{\star \star \star}(1.17)$ & $-0.24^{\star}(1.17)$ \\
\hline Total & 792 & $0.05(1.09)$ & $0.47^{\star \star \star}(1.16)$ & $0.17^{\star \star \star}(1.13)$ & $0.41^{\star \star \star}(1.14)$ & $0.20^{\star \star \star}(1.10)$ & $-0.13^{\star \star \star}(1.02)$ \\
\hline
\end{tabular}

Data expressed as mean (SD) of SDscores for height, weight, BMI, and triceps based on the British 1990 reference ${ }^{3-5}$ and the Tanner-Whitehouse (TW) standards. Significance levels for comparison of mean value with expected value of $0:{ }^{\star} \mathrm{p}<0.05 ;{ }^{\star \star} \mathrm{p}<0.01 ;{ }^{\star \star \star} \mathrm{p}<0.001$.

such that by the end of the study the children were aged between 9 and 11 years. All the participating schools were state primary schools sited outside the inner city area. Sociodemographic measures suggested that the schools were somewhat advantaged compared to Leeds schools according to the 1996 schools' census. The percentage of children from ethnic minorities ranged from $1 \%$ to $42 \%$ (sample mean $9 \%$ compared with $11 \%$ by census). Children entitled to free school meals (a measure of social disadvantage) ranged from $7 \%$ to $29 \%$ (sample mean $15 \%$ compared with $25 \%$ by census).

\section{AUXOLOGY}

The following measurements were taken: height, weight, triceps skinfold, mid abdominal circumference, and MUAC (mid upper arm circumference). Only weight, height, and triceps data are reported here. Height was measured using the method described by Tanner and colleagues, ${ }^{12}$ and recorded to the last $0.1 \mathrm{~cm}$. Children were weighed without shoes, jumpers, or sweatshirts and weight recorded to the last $0.1 \mathrm{~kg}$. The mean of three triceps measurements was used as recommended by Tanner and Whitehouse. ${ }^{9}$ All measurements were made by the same expert auxologist (JW) who has been employed as the outreach growth sister in Yorkshire for the past four years. The following equipment was used: a free standing Magnimetre stadiometer with rigid tripod mounting (Raven equipment), Seca 835 portable digital baby, toddler, and adult weighing scales, and Holtain Tanner-Whitehouse skinfold callipers.

DATA PROCESSING AND ANALYSIS

Using the Castlemead Growth Programme, ${ }^{10}$ height, weight, and triceps measurements were entered, BMI (wt/ht $\left.{ }^{2}\right)$ was calculated, and measurements were converted to SDscores using both the revised 1990 reference and the Tanner-Whitehouse standards. The following calculations were made for each standard:

- Mean (SD) score for boys and girls separately for ages $7,8,9,10$, and 11 years. Each year group was to the last completed year (that is, "7 year olds" included children aged 7.0 to $<8.0$ years). This allowed for a further comparison of the two standards, and trends with age
- Using the 1990 reference only, the change in SDscore for height, weight, and BMI each year was calculated for boys and girls. The numbers of children who crossed $\geqslant 0.67 \mathrm{SD}$ (one channel width) were identified for each measure

- Regression analysis was used to assess the significance of the age trends, both across subjects each year and within subjects over the three years (based on random effects regression).

\section{Results}

Only 21 children did not consent to participate. A total of 608 children were measured in 1996, of whom 540 were remeasured in 1997, and 499 in 1998 (some of whom were not measured in 1997). In addition 45 new children were measured in 1997, of whom 34 were remeasured in 1998 along with a further 41 new children. In total 694 children (378 boys and 316 girls) were measured in the course of the study, of whom 471 were measured on all three occasions, and 132 children twice.

Table 1 shows the anthropometry for the sample of children by age and sex. In theory, if the children were truly similar to those included in the growth reference, the mean SDscore should be zero (that is, should lie on the 50th centile) with a standard deviation of 1 . In practice, the mean SDscore, using the 1990 references for height and weight was 0.12 and 0.20 respectively, indicating that the Leeds children are marginally taller and heavier than the population used for the 1990 references. By comparison, when the Tanner-Whitehouse standards were used, the means for both height and weight were 0.45 and 0.46 respectively, indicating that the population mean shifted up by almost half a standard deviation (equivalent to approximately $5.5 \mathrm{~cm}$ and $4.5 \mathrm{~kg}$ ). For both standards the standard deviation for the group was close to 1 as expected.

The Tanner-Whitehouse triceps SDscore for the group is largely negative, although close to zero. This is in contrast to the 1990 BMI score, the other measure of obesity, and also to the Tanner-Whitehouse weight and height results that are appreciably larger.

For both height and weight, the discrepancy between the two standards is evident at all ages. In addition a trend of increasing mean SDscore 
Table 2 The annual change in SDscore (SDS) for each age group using the 1990 reference, expressed as mean (SD)

\begin{tabular}{lrlll}
\hline Age & $n$ & Change in height SDS & Change in weight SDS & Change in BMI SDS \\
\hline Boys & 27 & $-0.07(0.17)$ & $0.03(0.20)$ & $0.11(0.29)$ \\
$7+\mathrm{y}$ & 165 & $-0.02(0.20)$ & $0.09(0.27)$ & $0.17(0.40)$ \\
$8+\mathrm{y}$ & 261 & $-0.02(0.21)$ & $0.04(0.23)$ & $0.07(0.33)$ \\
$9+\mathrm{y}$ & 121 & $0.00(0.18)$ & $0.03(0.29)$ & $0.00(0.44)$ \\
$10+\mathrm{y}$ & & & & \\
Girls & 18 & $-0.04(0.18)$ & $0.02(0.43)$ & $0.04(0.49)$ \\
$7+\mathrm{y}$ & 148 & $-0.03(0.21)$ & $0.07(0.27)$ & $0.11(0.34)$ \\
$8+\mathrm{y}$ & 211 & $0.01(0.24)$ & $0.09(0.32)$ & $0.00(0.46)$ \\
$9+\mathrm{y}$ & 92 & $0.11(0.25)$ & $0.20(0.24)$ & $0.14(0.31)$ \\
$10+\mathrm{y}$ & & &
\end{tabular}

Table 3 Percentage of children (95\% confidence intervals) crossing at least one channel up or down in a year using the 1990 reference (SDscore increasing by at least 0.67)

\begin{tabular}{|c|c|c|}
\hline & Boys $(n=317)$ & Girls $(n=257)$ \\
\hline \multicolumn{3}{|c|}{ Percentage crossing at least one channel up } \\
\hline Height & $0.9 \%(0.4-2.7)$ & $1.2 \%(0.5-3.4)$ \\
\hline Weight & $1.6 \%(0.8-3.6)$ & $1.9 \%(1.0-4.5)$ \\
\hline BMI & $5.0 \%(3.3-8.1)$ & $5.1 \%(3.2-8.5)$ \\
\hline \multicolumn{3}{|c|}{ Percentage crossing at least one channel down } \\
\hline Height & $0.3 \%(0.1-1.7)$ & $0.0 \%(0.0-1.4)$ \\
\hline Weight & $0.3 \%(0.1-1.7)$ & $0.4 \%(0.1-2.1)$ \\
\hline BMI & $0.9 \%(0.4-2.7)$ & $2.3 \%(1.2-5.0)$ \\
\hline
\end{tabular}

with age is seen for weight in boys and both height and weight for girls. This trend with age is also reflected in the BMI. Based on the British 1990 reference, ages and sexes and years combined, the age trends are highly significant $(\mathrm{p} \sim 0.001)$ for weight and BMI, but far from significance for height. So older children are heavier and fatter, but no taller. After adjusting for age there is no evidence of a trend from one year to the next $(p \sim 0.2)$, so for example the average 9 year old child weighs the same in 1996, 1997, and 1998.

Table 2 shows the change in SDscore for each age group each year. The anticipated delta SDscore should be zero, and this was found to be so for all three measures of height, weight, and BMI. The standard deviation of the age group gives an idea of the variation within the group. The standard deviations are mostly below 0.33 (half of one channel width) indicating little movement of clinical significance between channels for the majority of children.

Table 3 shows the numbers of children who were observed to cross one or more channel widths in either direction. In total $1 \%$ of children crossed channels either up or down for height, while $2 \%$ crossed up for weight, increasing to $5 \%$ for BMI. There is no corresponding number of children crossing down for weight and BMI, suggesting an increase in weight gain for the population as a whole. Expressing this another way, the relative risk of crossing up a channel width for weight (as opposed to down) is 5 .

Table 4 summarises the trends in height, weight, and BMI SDscore over time for the 603 subjects measured more than once, a total of

Table 4 Mean annual change in SDscore (SDS) as assessed by random effects regression (British 1990 reference, sexes combined)

\begin{tabular}{llll}
\hline & $\begin{array}{c}\text { Regression coefficient } \\
\text { (SDS units per year) }\end{array}$ & Standard error & Significance \\
\hline Height & -0.003 & 0.005 & $\mathrm{p}=0.6$ \\
Weight & 0.078 & 0.007 & $\mathrm{p}<0.0001$ \\
BMI & 0.100 & 0.009 & $\mathrm{p}<0.0001$ \\
\hline
\end{tabular}

1766 measurements. The results summarise those of table 2, showing no trend in height but very highly significant positive trends in both weight and BMI. The size of the trend, particularly for BMI, is potentially alarming, at 0.1 SDscores per year. At this rate, mean BMI will increase by one channel width within seven years.

\section{Discussion}

The collection of growth data, by an expert auxologist, on a large cohort of children in Leeds gave us the opportunity to evaluate the new growth references for an age range of children previously unreported. When the children's growth was analysed in relation to the 1990 and the Tanner-Whitehouse standards, it was evident that the new standards suited this group of children better than the old. Indeed one can state that if we were to persist in using the Tanner-Whitehouse standards, children on average would be plotted to lie at a position up to half a standard deviation (one to two thirds of a channel width) higher than they should for both height and weight. This would be of particular concern for short and underweight children, many of whom would be erroneously plotted well into the normal range.

This sample of Leeds children is taller and heavier than the British 1990 reference population, which may reflect the relative advantage of the schools included in the APPLES project.

Our study builds on an earlier study from Glasgow $^{6}$ which came to similar conclusions in a younger age group. They found that their children approximated the new references, but were heavier and longer compared with the Tanner-Whitehouse standards. These two studies together therefore provide some validation of the new reference, and support the recommendation ${ }^{3}$ that the new growth charts should be adopted across the UK, at least for prepubertal children. Confirmation is still required for older children and adolescents, which will be a harder task both in terms of the practicality of going into secondary schools and the complication of puberty influencing growth.

The Glasgow study ${ }^{6}$ differed from ours in that they found the Tanner-Whitehouse triceps standards to be inappropriate, with the Glasgow children's skinfolds significantly less than the standards. In our sample this discrepancy was less evident, and perhaps the need for revised standards for older children is less imperative. Yet according to the TannerWhitehouse standards the Leeds children are tall and heavy while their triceps skinfolds are below average. This suggests that the triceps standards are out of step with the corresponding weight and height standards.

As children in this study were measured annually, some light is thrown on current children's patterns of growth. This has particular relevance if the new charts are used for monitoring growth over a period of time, which is their principal purpose in the hospital setting at least. Paediatric experience and wisdom contends that it is unusual for children in this age group to cross centile lines for height, and 
that growth velocity is constant in the years leading up to puberty. To date, channel crossing on the 1990 growth charts has only been assessed using longitudinal data on height collected from French children. ${ }^{8}$ This study supports this finding for height, with no measurable trend over time, and it was quite unusual for children to cross a channel width over the period of one year. The situation for weight was rather different and although it was unusual for children to cross down for weight, it was much more likely for them to cross up. The same was true for BMI.

The observation that BMI SDscore increased steeply with age and the related finding that an appreciable number of children crossed BMI channels upwards is worrying. The correlation of adult obesity to childhood obesity increases with age, and increases of BMI by a whole channel width in the space of a few years may well prove to be a marker for future obesity with all the risks that that entails.

The trend of increasing BMI with age (tables 1 and 4) is not a secular trend as such-the same trend is seen in each year group. The age range $7-11$ is clearly a period when children cross BMI centiles upwards relative to the British 1990 reference. There are two possible reasons for this: either obesity is genuinely increasing, or else the reference centiles are wrong. The latter alternative is unlikely, as the reference centiles during primary school age were based on over 10500 English and Scottish children from the National Study of Health and Growth measured in 1989/90. ${ }^{5}$ In addition the trend is present only for weight and BMI, not height. So the conclusion must be that compared to the pattern in 1990, obesity now rises steeply during time at primary school. The finding is particularly disturbing given the fact that these schoolchildren were exposed to a health promotion programme focused on encouraging increased amounts of physical activity and healthier eating.

This study therefore provides support for the adoption of the new growth reference. More work is required in studying its use and limitations in older children and perhaps in other geographical areas as well. Other longitudinal studies are needed in order to appreciate children's patterns of growth and to confirm the trends observed here for BMI.

This research was supported by a grant from Northern and Yorkshire Region Research and Development Unit. We thank Charlotte Wright and the other anonymous referee for helpful comments on previous versions of the paper. TJC was involved in the development of the British 1990 growth reference, though has no financial interest in the charts.

1 Tanner JM, Whitehouse RH, Takaishi M. Standards from birth to maturity for height, weight, height velocity and weight velocity: British children, 1965. Arch Dis Child 1996;41:454-71.

2 Tanner JM, Whitehouse RH, Takaishi M. Standards from birth to maturity for height, weight, height velocity and weight velocity: British children, 1965. Arch Dis Child 1996;41:613-35.

3 Freeman JV, Cole TJ, Chinn S, Jones PRM, White EM, Preece MA. Cross sectional stature and weight reference Preece MA. Cross sectional stature and weight reference
curves for the UK, 1990. Arch Dis Child 1995;73:17-24.

4 Cole TJ, Freeman JV, Preece MA. Body mass index reference curves for the UK, 1990. Arch Dis Child 1995;73: refere $25-9$.

5 Cole TJ, Freeman JV, Preece MA. 1990 growth reference centiles for weight, height, body mass index and head circumference fitted by maximum penalised likelihood. Stat Med 1998;17:407-29.

6 Savage SAH, Reilly JJ, Edwards CA, Durnin JVGA. Adequacy of standards for assessment of growth and nutritional status in infancy and early childhood. Arch Dis Child 1999;80:121-4

7 Sahota P, Rudolf MCJ, Dixey R, Hill AJ, Barth JH. APPLES: a school-based intervention to reduce obesity risk factors. Fournal of the International Association for Study of Obesity 1998;22(suppl 3):S62.

8 Cole TJ. Growth monitoring with the British 1990 growth reference. Arch Dis Child 1997;76:47-9.

9 Tanner JM, Whitehouse RH. Standards for subcutaneous Tanner JM, Whitehouse RH. Standards for subcutaneous
fat in British children. Percentiles for thickness of skinfolds over triceps and below scapula. BMF 1962;i:446-50.

10 Cole TJ. Castlemead Growth Programmes. Welwyn Garden City: Castlemead Publications, 1993. 